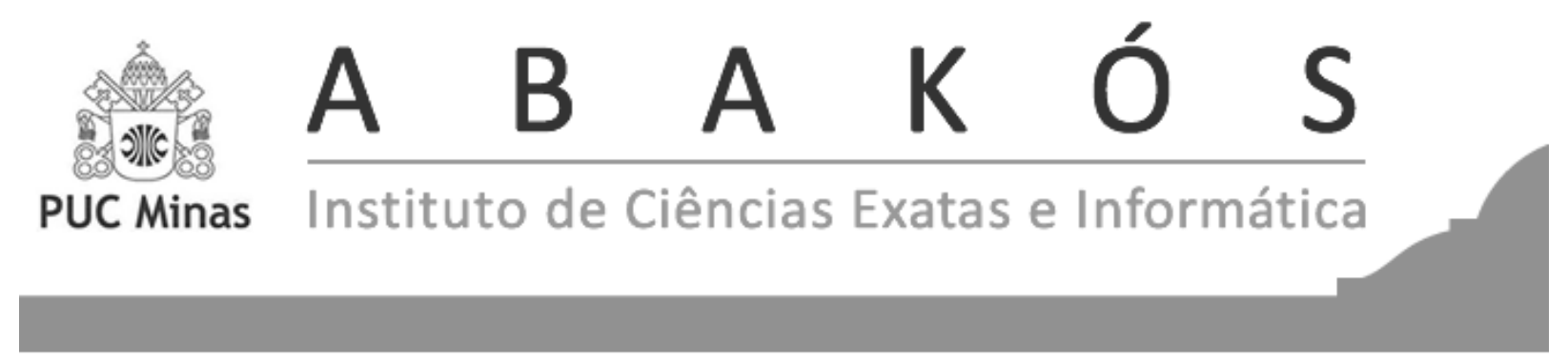

\title{
Contribuições da Tecnoracia e da Etnomatemática para a Promoção da Educação Financeira de Estudantes Surdos*
}

Contributions of Technoracy and Ethnomathematics to the Promotion of Financial Education for Deaf Students

\author{
Rodrigo Carlos Pinheiro ${ }^{1}$ \\ Milton Rosa ${ }^{2}$
}

\begin{abstract}
Resumo
Apresentamos, neste artigo, alguns resultados obtidos em uma pesquisa de Mestrado Profissional em Educação Matemática, que está relacionada com o desenvolvimento da Educação Financeira de jovens e adultos Surdos, que se comunicam em Libras, por meio da perspectiva etnomatemática. Especificamente, procuramos compreender a relação dos resultados desse estudo com um dos elementos do Currículo Trivium para a Matemática, denominado por Tecnoracia, que foi proposto D'Ambrosio, em 1999. Desse modo, essa reconceituação curricular é composta pela literacia (instrumentos comunicativos), materacia (instrumentos analíticos) e tecnoracia (instrumentos materiais e tecnológicos). A abordagem metodológica foi qualitativa, com a utilização dos pressupostos da Teoria Fundamentada nos Dados (Grounded Theory). Da fase analítica, foi possível inferir que o programa etnomatemática possibilitou o fornecimento dos instrumentos comunicativos, analíticos, materiais e tecnológicos, que são característicos da cultura Surda para que os alunos pudessem resolver as situações-problema propostas em sala de aula.
\end{abstract}

Palavras-chave: educação financeira. etnomatemática. tecnoracia. alunos Surdos.

\footnotetext{
* Submetido em 23/10/2018 - Aceito em 01/04/2019

${ }^{1}$ Doutorando em Educação: Conhecimento e Inclusão Social pela Universidade Federal de Minas Gerais , Brasil rodrigopinheiro506@gmail.com

${ }^{2}$ Doutor em Educação em Liderança Educacional pela California State University, Sacramento - CSUS. Professor Associado da Universidade Federal de Ouro Preto - UFOP, Brasil - milton.rosa@ufop.edu.br
} 


\begin{abstract}
We present, in this article, some results obtained in a Professional Masters in Mathematics Education research, which is related to the development of Financial Education through an ethnomathematical perspective of hearing-impaired youth and adult students, who communicate in Libras (Brazilian sign language). Specifically, we attempted to understand the relation of the results of this study to one of the elements of the Trivium Curriculum for Mathematics, called Technoracy, which was proposed by D'Ambrosio, in 1999. In this way, this curricular reconceptualization is composed of literacy (communicative instruments), matheracy (analytical instruments), and technoracy (material and technological instruments). The methodological approach was qualitative by using Grounded Theory assumptions. From the analytical phase, it was possible to infer that the ethnomathematics program enabled to supply students with communicative, analytical, and material and technological instruments that are characteristic of the Deaf culture so that they could solve problems and situations proposed in classrooms.
\end{abstract}

Keywords: financial education. ethnomathematics. technoracy. Deaf students. 


\section{INTRODUÇÃO}

O processo de ensino e aprendizagem em Matemática para alunos Surdos é considerado como um desafio para muitos investigadores, pois esses estudantes possuem características peculiares, por exemplo, uma língua própria e uma cultura específica, que demandam estratégias diferenciadas e capacitação dos professores que estão envolvidos no processo educacional (PINHEIRO, 2017).

Desse modo, a educação matemática para Surdos tem sido motivo de debates, bem como da condução de pesquisas relacionadas com essa temática; contudo, a revisão de literatura aponta que poucas investigações têm sido produzidas com relação à Educação Financeira para os alunos Surdos na perspectiva da Etnomatemática.

Além disso, Gil (2008) argumenta que alguns estudos mostram que, devido à complexidade da linguagem matemática, os alunos Surdos podem apresentar dificuldades relacionadas com a interpretação dos enunciados das atividades propostas em sala de aula e, também, com a resolução de situações-problema contextualizadas.

Nesse contexto, a Educação Financeira pode contribuir para o processo de formação de indivíduos ativos e autônomos que sejam capazes de tomar decisões responsáveis (ALVES, 2014). Portanto, é importante incentivar discussões sobre a utilização de metodologias inovado$\operatorname{ras}^{3}$ para a Educação Financeira, baseadas nos pressupostos do Programa Etnomatemática, pois essa abordagem visa contribuir para o desenvolvimento da cidadania, da criticidade, da reflexão e, também, para o entendimento e a compreensão dos conteúdos matemáticos da população escolar Surda.

Como os estudantes Surdos pertencem a um grupo cultural distinto, que desenvolve a sua própria língua - a Libras - é importante que o processo de ensino e aprendizagem em matemática seja ajustado para a sua cultura, pois em geral, esses alunos classificam e representam as situações-problema que enfrentam em seu cotidiano escolar de acordo com as experiências vivenciadas em seu dia a dia. Dessa maneira, D’Ambrosio (2009) afirma que existe a necessidade da incorporação dos aspectos cotidianos da Matemática, da contextualização de seus conteúdos e da utilização de instrumentos tecnológicos no processo de ensino e aprendizagem em matemática.

Assim, após a realização de um levantamento bibliográfico sobre os estudos relacionados à Educação Matemática e Financeira para alunos Surdos e, por meio dos questionamentos e anseios do primeiro autor deste trabalho, sob a orientação do segundo, elaborou-se uma questão de investigação que explorasse profundamente a problemática desse estudo: Como o Programa Etnomatemática pode contribuir para o desenvolvimento da Educação Financeira de alunos Surdos que se comunicam em Libras?

Norteados por essa problemática, essa pesquisa foi conduzida com 20 alunos Surdos que

\footnotetext{
${ }_{3}^{3}$ Nesse estudo, as metodologias inovadoras se opõem ao método de ensino tradicional, pois são consideradas como um conjunto de estratégias que visam facilitar o processo de ensino e aprendizagem em matemática, como, por exemplo, a utilização de jogos, as dinâmicas e as aulas interativas com participação ativa dos alunos (SANTOS, 2005).
} 
se comunicam em Língua Brasileira de Sinais (Libras). Dessa maneira, apresentamos alguns resultados obtidos nessa pesquisa de Mestrado Profissional em Educação Matemática, que está relacionada com o desenvolvimento da Educação Financeira de jovens e adultos Surdos sob um olhar etnomatemático.

Além disso, abordamos a relação desses resultados com um dos elementos do Currículo Trivium para a Matemática, denominado por Tecnoracia, que foi proposto D’Ambrosio (1999). Desse modo, essa reconceituação curricular é composta pela literacia (instrumentos comunicativos), materacia (instrumentos analíticos) e tecnoracia (instrumentos materiais e tecnológicos). Esses três componentes são importantes para o desenvolvimento da ação pedagógica do programa etnomatemática para alunos Surdos

a) Literacia: está relacionada com os instrumentos comunicativos que possibilitam o desenvolvimento da capacidade de os indivíduos processarem as informações escritas e faladas, incluindo a leitura, a escrita, o cálculo, o diálogo, a mídia e a internet na vida cotidiana.

b) Materacia: está relacionada com a utilização dos instrumentos analíticos que possibilitam o desenvolvimento da capacidade de os indivíduos interpretarem e analisarem os sinais e os códigos presentes no cotidiano, de proporem e utilizarem os modelos e as simulações da vida diária para que possam elaborar abstrações sobre as representações do mundo real.

c) Tecnoracia: está relacionada com a utilização de instrumentos materiais que possibilitam o desenvolvimento da capacidade de os indivíduos usarem e combinarem ferramentas tecnológicas simples ou complexas, inclusive o próprio corpo, para avaliar as suas possibilidades e limitações, bem como a sua adequação às necessidades e situações-problema diversas enfrentadas no cotidiano.

Consequentemente, Rosa e Orey (2015) afirmam que esse currículo pode favorecer a valorização do conhecimento matemático escolar, bem como das ideias, procedimentos e práticas matemáticas relacionadas com a Educação Financeira, pois destacam a sua relação com a etnomatemática e, também, com a tecnoracia.

\section{ASPECTOS METODOLÓGICOS DA PESQUISA}

Esse estudo foi realizado com 20 alunos Surdos, que se comunicam em Língua Brasileira de Sinais (Libras), de duas turmas, denominadas por A e B, estudantes na modalidade da Educação de Jovens e Adultos (EJA), dos anos finais do Ensino Fundamental, em uma escola pública de caráter especial, localizada na região metropolitana de Belo Horizonte, no estado de Minas Gerais. Os dados brutos foram coletados pelo primeiro autor durante as aulas de matemática que eram ministradas em Libras. Ressaltamos que os nomes dos participantes foram 
codificados por letras para indicar a turma, e por números para indicar o gênero dos participantes, pois visavam a preservação de suas identidades.

Para coleta de dados, foram utilizados dois questionários, uma entrevista semiestruturada com 11 participantes e as anotações do diário de campo. Esses dados foram analisados e interpretados no decorrer da condução dessa pesquisa de acordo com o referencial teórico embasado na Etnomatemática, na Cultura Surda e na Educação Financeira e, também, com a utilização dos pressupostos metodológicos da Teoria Fundamentada nos Dados (Grounded Theory), que foram utilizados para a elaboração e aplicação de três blocos de atividades matemática propostos para o registro documental, que estavam relacionadas com conteúdos propostos pela Educação Financeira.

Esses blocos de atividades foram planejados sob a perspectiva do Programa Etnomatemática para valorizar a cultura dos alunos Surdos, utilizando a Língua de Sinais como principal meio de comunicação e respeitando as suas limitações em relação à Língua Portuguesa. O primeiro bloco de atividades referiu-se à História da Moeda e do Sistema Monetário Brasileiro, o segundo bloco foi sobre o tema Porcentagem enquanto o terceiro estava relacionado com o conteúdo de Lucro e Desconto.

De acordo com os pressupostos da Teoria Fundamentada, o conjunto dos dados brutos, denominado por amostragem teórica, foi coletado em Libras durante a realização desse estudo. Posteriormente, esses dados foram traduzidos para o português e transcritos para facilitar a sua análise, bem como para possibilitar a interpretação das informações obtidas durante o desenvolvimento do processo analítico. Em seguida, os dados foram submetidos às codificações aberta e axial para a elaboração das categorias de análise, que auxiliaram na interpretação dos resultados obtidos.

\section{ETNOMATEMÁTICA E TECNORACIA}

O Programa Etnomatemática possui uma conceituação ampla, por isso é importante entender quais são os seus objetivos e como a sua ação pedagógica pode ser aplicada em sala de aula. Nesse contexto, a Etnomatemática pode ser definida como um:

(...) programa de pesquisa em história e filosofia da Matemática, com implicações pedagógicas, que se situa num quadro muito amplo. Seu objetivo maior é dar sentido a modos de saber e de fazer das várias culturas e reconhecer como e por que grupos de indivíduos, organizados como famílias, comunidades, profissões, tribos, nações e povos, executam suas práticas de natureza Matemática, tais como contar, medir, comparar, classificar (D'AMBROSIO, 2008, p .7).

De acordo com essa asserção, um dos principais objetivos da etnomatemática é analisar as práticas matemáticas realizadas pelos membros de um grupo cultural específico. Além disso, esse programa possui uma dimensão sociocrítica que pode esclarecer a natureza do conhecimento matemático dos membros de tal grupo (D’AMBROSIO, 1990). 
Nesse contexto, a educação matemática para Surdos na perspectiva da Etnomatemática pode se tornar um caminho promissor para que o processo de ensino e aprendizagem em matemática ocorra efetivamente, visto que os educandos Surdos compõem um grupo cultural específico marcado por uma língua própria, a Libras, e por uma cultura diferenciada, a Cultura Surda.

Nessa ótica, a educação matemática evidencia a necessidade de valorizar as experiências socioculturais dos alunos Surdos para que possam vincular os próprios conhecimentos matemáticos àqueles apresentados pelas instituições de ensino. Além disso, é importante utilizar instrumentos materiais que sejam condizentes com a realidade sociocultural desses estudantes, como, por exemplo, os recursos visuais e tecnológicos. É importante ressaltar que as calculadoras, os celulares e os computadores podem contribuir para o progresso escolar desses alunos.

Nesse direcionamento, Rosa e Orey (2015) afirmam que é necessário integrar a utilização de recursos tecnológicos como, por exemplo, os computadores, os softwares, ascalculadoras e os equipamentos digitais no processo de ensino e aprendizagem em matemática, a fim de capacitar os alunos para mediar e moldar as suas habilidades matemáticas de pensamento e numeracia ${ }^{4}$. Dessa maneira, Rosa e Orey (2015) argumentam que, essa capacidade que os indivíduos desenvolvem para combinar diferentes recursos materiais e tecnológicos, para que possam criticar a sua utilização e avaliar as suas possibilidades e limitações em diversas situações cotidianas, que são necessárias para possibilitar a tomada de decisões, é denominada por Tecnoracia, que pode ser considerada como a:

(...) familiaridade crítica e reflexiva dos indivíduos com a tecnologia (...). Essa familiaridade permite que eles utilizem instrumentos materiais e tecnológicos para avaliar as diversas formas de apresentar e representar as ideias e práticas matemáticas e avaliar a razoabilidade dos resultados e a sua contextualização (...) (ROSA; OREY, 2015, p .593-594, tradução nossa) $)^{5}$.

A importância do conhecimento tecnológico manifesta-se na necessidade de os alunos Surdos poderem utilizar os instrumentos materiais e tecnológicos disponíveis para que possam determinar a solução para as diversas situações-problema enfrentadas em seu cotidiano e que podem ser propostas em sala de aula (D’AMBROSIO, 2008).

Consequentemente, a tecnoracia pode se manifestar em instrumentos tecnológicos que podem traduzir as formas distintas que os indivíduos desenvolvem para lidar com os ambientes: natural, social, cultural, político e econômico, que possibilitam a incorporação de diversos modos de explicações, crenças, tradições, mitos e símbolos (D’AMBROSIO, 2008). Assim, para

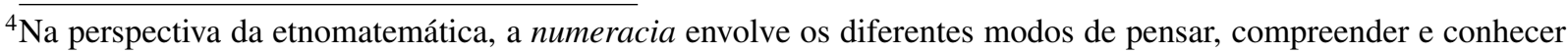
a matemática e os seus usos em ambientes diversos, pois esse programa se relaciona com a descoberta e a análise dos processos de origem, transmissão, difusão e institucionalização de conhecimentos matemáticos adquiridos em contextos culturais distintos (ROSA; OREY, 2006). Desse modo, a numeracia tem relação com o desenvolvimento das diversas maneiras do saber/fazer matemático que se relaciona com as ideias, noções, procedimentos e práticas matemáticas contextualizadas por meio da utilização de uma ação pedagógica inovadora para o currículo matemático (D'AMBROSIO, 1999).

${ }^{5}$ (...) individuals' critical and reflexive familiarity with technology (...). This familiarity allows them to use material and technological instruments in order to evaluate diverse ways to present and represent mathematical ideas and practices, and to assess the reasonableness of the results and their contextualization (...).
} 
Rosa e Orey (2006), o programa etnomatemática postula uma proposta política embutida na ética e enfoca a recuperação da dignidade cultural dos membros de grupos culturais distintos.

Por conseguinte, a tecnoracia pode ser considerada como a capacidade que os indivíduos possuem para utilizar e combinar, de maneira crítica, diferentes ferramentas tecnológicas e instrumentos materiais, das mais simples às mais complexas, bem como avaliar as suas possibilidades e limitações para atender às suas necessidades em situações cotidianas distintas (ROSA; OREY, 2015).

Então, como a sociedade contemporânea é altamente tecnológica, a tecnoracia tem um papel importante, pois auxilia os indivíduos a atuarem sobre o mundo utilizando ferramentas materiais e instrumentos tecnológicos, dos mais simples aos mais complexos, para resolver os problemas enfrentados diariamente (ROSA; OREY, 2015).

A importância desse conhecimento se manifesta com a necessidade que os alunos têm para utilizar os instrumentos materiais e tecnológicos disponíveis para a solução das situaçõesproblema propostas nas salas de aula (D’AMBROSIO, 2008). No entanto, é importante que as situações-problema utilizadas sejam contextualizadas para que possibilitem aos alunos o emprego de estratégias para resolvê-las com a aplicação de sua própria tecnoracia.

Nesse sentido, a utilização do próprio corpo pode ser considerada como um instrumento material ou tecnológico que está relacionado com a Libras e, consequentemente, com a Cultura Surda e, também, com a Tecnoracia. Nesse contexto, pode-se inferir que é possível utilizar: a língua de sinais, os jargões, as técnicas, as estratégias e os códigos comportamentais dos alunos Surdos como instrumentos materiais e tecnológicos, que podem contribuir para o desenvolvimento do processo de ensino e aprendizagem de conteúdos matemáticos em sala de aula.

Nesse direcionamento, selecionamos um episódio da análise dos dados e a interpretação dos resultados obtidos nesse estudo, referente a uma aula sobre o Sistema Monetário, no qual um participante utilizou uma estratégia específica dos membros da Cultura Surda para a resolução de uma dada situação-problema. Esse episódio ocorreu devido à curiosidade de alguns participantes em relação à adição de dinheiro e, então, foi proposta a seguinte situação-problema: $S e$ eu tenho quatro moedas iguais de 25 centavos, quanto tenho no total?

A análise das respostas dadas para essa questão mostrou que três participantes da turma responderam, imediatamente, que a resposta é igual a um real, enquanto quatro participantes não responderam a esse questionamento. No entanto, o participante $A 7$ solicitou ao primeiro autor se poderia explicar para os demais participantes o procedimento que havia utilizado para resolver essa questão.

As imagens representadas pelas figuras de 01 a 04 mostram a reprodução da fala do participante $A 7$ para explicar a maneira própria (jargão etnomatemático) que utilizou para resolver e explicar a questão proposta em sala de aula. Ressalta-se que essa sequência de figuras está sendo apresentada dessa maneira por causa da dificuldade da transcrição dos movimentos do participante $A 7$, que foram realizados em Libras.

Nesse contexto, a figura 01 mostra o primeiro autor desse artigo reproduzindo a explicação dada pelo participante $A 7$ para representar as quatro moedas de 25 centavos. 


\section{Figura 1 - Representação em Libras das quatro moedas de 25 centavos}

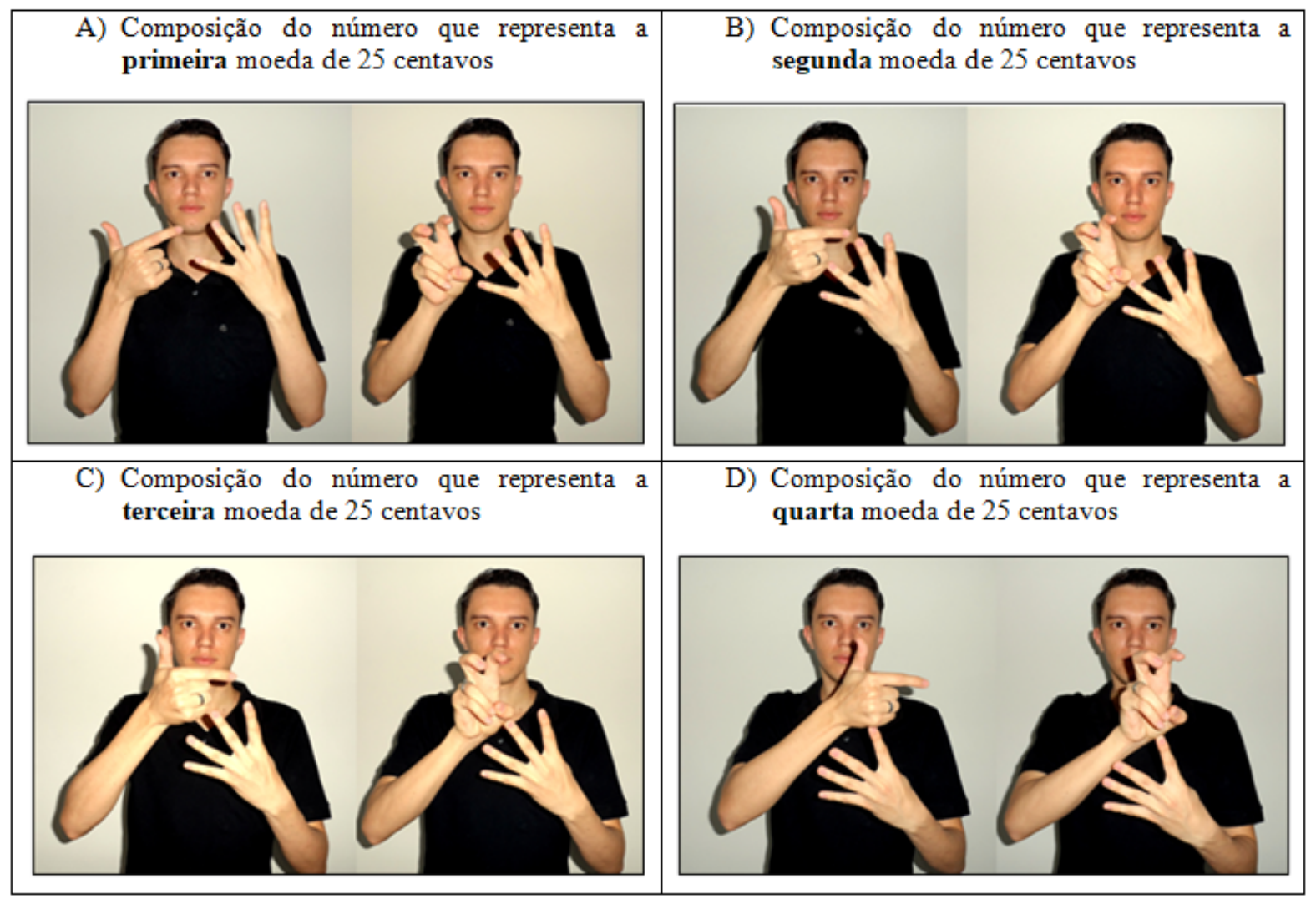

Fonte: Arquivo dos autores.

As fotografias da imagem $A$, na figura 01 , representam os números 2 e 5 , respectivamente. Essa imagem expressa o número 25, em Libras, que é formado próximo ao dedo mindinho, indicando a primeira moeda de 25 centavos. Na imagem $B$, da figura 01 , as fotografias representam os números 2 e 5, respectivamente. Essa imagem expressa o número 25, em Libras, sendo formado próximo ao dedo anelar, indicando a segunda moeda de 25 centavos. Similarmente, a imagem $C$ representa a terceira moeda de 25 centavos, que foi sinalizada próximo ao dedo médio, enquanto a imagem $D$ representa a quarta moeda de 25 centavos e foi sinalizada próxima ao dedo indicador.

A imagem $A$, da figura 02 , indica a junção da primeira e segunda moedas de 25 centavos, que foram representadas pelos dedos mindinho e anelar. As fotografias da imagem $B$, na figura 02 , representam os números 5 e 0 , respectivamente, que correspondem ao número 50 em Libras, ou seja, a junção das duas primeiras moedas de 25 centavos é igual a 50 centavos. A imagem $C$, da figura 02 , indica a junção da terceira e quarta moedas de 25 centavos, que foram representadas pelos dedos médio e indicador. As fotografias da imagem $D$, na figura 02 , representam os números 5 e 0 , respectivamente, que correspondem ao número 50 em Libras, ou seja, a junção das duas últimas moedas de 25 centavos é igual a 50 centavos. 
Figura 2 - Representação da junção das quatro moedas de 25 centavos

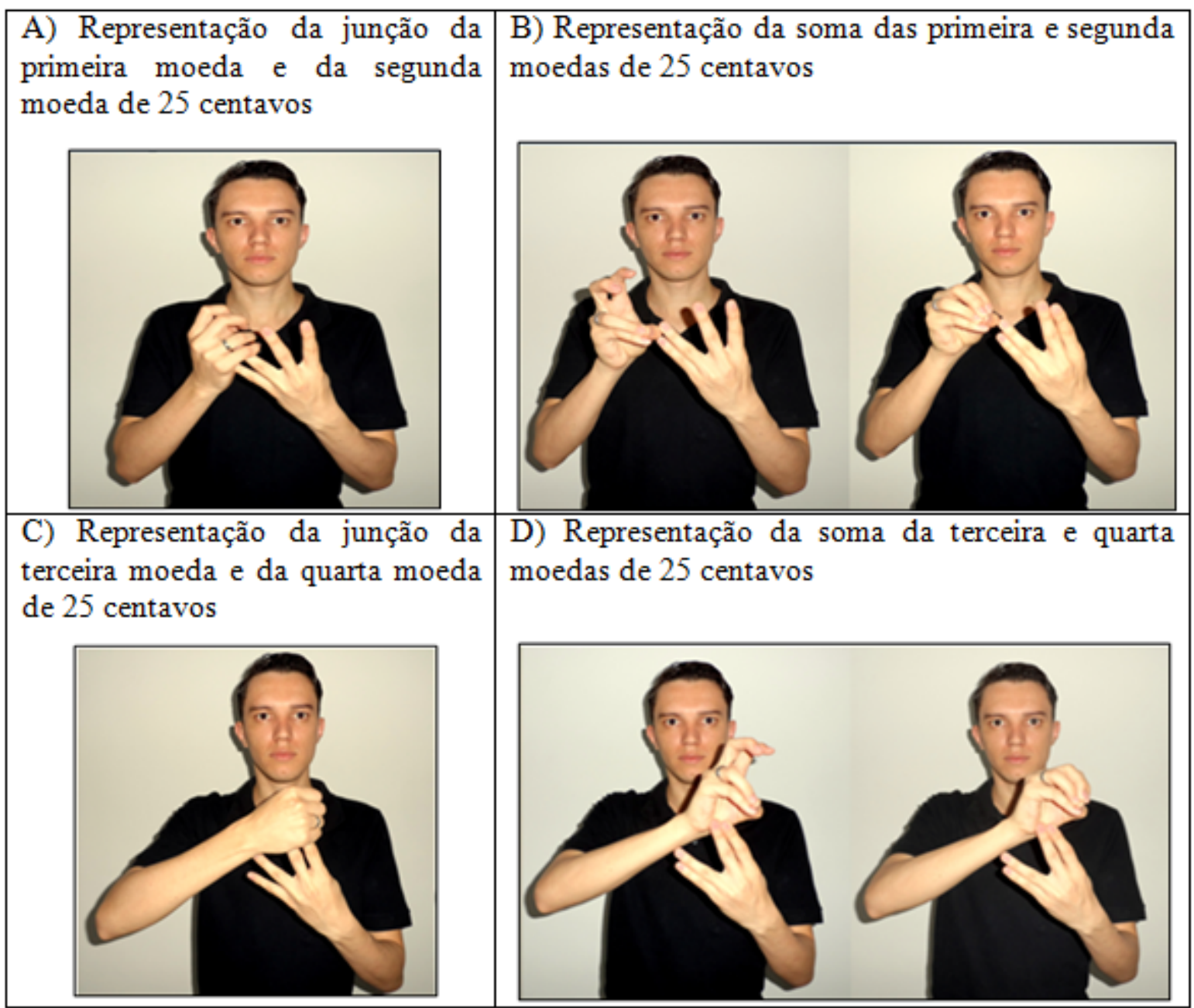

Fonte: Arquivo dos autores.

Figura 3 - Representação da soma das quatro moedas de 25 centavos

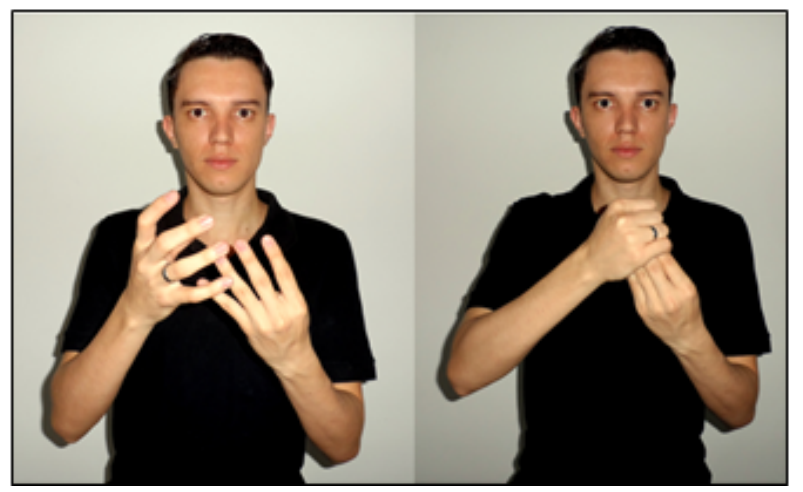

Fonte: Arquivo do primeiro autor.

As duas imagens representadas na figura 03 mostram a junção de todos os dedos, ou seja, a soma das quatro moedas. 
Figura 4 - Representação do valor de 1 real

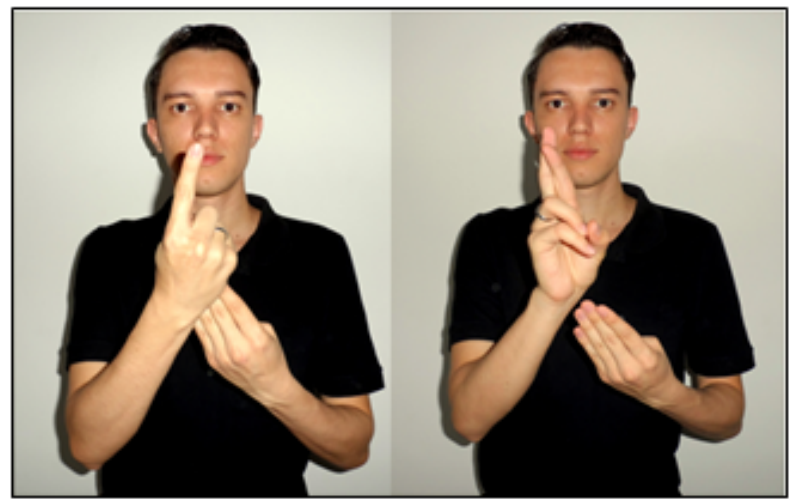

Fonte: Arquivo do primeiro autor.

A representação das duas imagens da figura 04 mostra que a junção de todos os dedos, ou seja, a soma das quatro moedas que é igual a um real, sendo que a primeira imagem indica o número 1 e a segunda imagem representa a palavra real.

Esse episódio mostra que, de acordo com Strobel (2008), essa experiência visual significa a utilização da visão dos alunos Surdos, em substituição à audição, como um meio de comunicação relacionado com a tecnologia de leitura. Assim, a Cultura Surda se origina da experiência visual desses alunos, sendo representada pela língua de sinais, pelo modo diferente de ser dos Surdos, de se expressar, de conhecer o mundo, de entender as artes e de adquirir o conhecimento científico e acadêmico.

\section{ALGUNS RESULTADOS}

Nesse estudo, o trabalho docente com a educação financeira para os alunos Surdos, por meio da perspectiva etnomatemática, pode ser considerado como um exercício de criatividade, pois representou mais do que a simples transmissão de conhecimento, de teorias e conceitos prontos para esses participantes.

Nesse sentido, esse programa possibilitou o fornecimento dos instrumentos comunicativos, analíticos, materiais e tecnológicos, que são característicos de sua própria cultura para que pudessem resolver as situações-problema propostas em sala de aula. Então, o primeiro autor utilizou estratégias diferenciadas, interagiu com os participantes, procurando conhecer as diversidades culturais e sociais presentes em sua sala de aula para que pudesse buscar novos conhecimentos para serem trabalhados em sua prática docente.

Desse modo, é importante destacar que diversos aspectos positivos emergem na sala de aula à medida que os professores enalteçam a troca de experiência entre os estudantes como uma forma de aprendizagem, como, por exemplo, a "confiança dos alunos na própria capacidade e na dos outros para construir conhecimentos matemáticos, o empenho em participar ativamente das atividades em sala de aula e o respeito ao modo de pensar dos colegas" (BRASIL, 1998, p .30)

Os resultados obtidos nesse estudo também corroboram com o ponto de vista de D' Ambrosio 
(2008) ao considerar que a:

(...) etnomatemática propõe uma pedagogia viva, dinâmica, de fazer o novo em resposta a necessidades ambientais, sociais, culturais, dando espaço para a imaginação e para a criatividade. É por isso que na pedagogia da etnomatemática, utiliza-se muito a observação, a literatura, a leitura de periódicos e diários, os jogos, o cinema, etc. Tudo isso, que faz parte do cotidiano, tem importantes componentes matemáticos (p. 10).

Por conseguinte, durante o desenvolvimento desse estudo, foi possível inferir que a perspectiva etnomatemática direcionou uma busca de conexões da matemática com o cotidiano dos participantes mediante a elaboração de atividades contextualizadas e condizentes com o seu ambiente sociocultural, com a utilização da Libras, que pode ser considerada como um instrumento tecnológico por meio do qual os alunos Surdos utilizam o próprio corpo para se comunicar na modalidade gesto-visual.

De acordo com a interpretação dos resultados obtidos nesse estudo, infere-se que os estudantes Surdos conseguiram conectar as atividades propostas em sala de aula com a realidade que vivenciam em seu cotidiano. Por exemplo, quando o primeiro autor estava explicando a última questão da atividade 02 intitulada: Trabalhando com dinheiro, o participante B25 interrompeu a sua explicação comentando que o "Feijão tá muito caro, tá $\mathrm{R} \$ 4,50$. (...). Quando os alimentos estão acabando eu vou ao supermercado e faço as compras. E agora o preço do feijão aumentou muito".

Assim, os resultados desse estudo mostram que o processo de ensino e aprendizagem em matemática, direcionado para a Educação Financeira, deve considerar o conhecimento matemático construído no cotidiano dos alunos como um instrumento para se alcançar os objetivos educacionais propostos em sala de aula. Essa perspectiva possibilita a caracterização de ações pedagógicas desenvolvidas por meio de atividades contextualizadas, que são originadas no ambiente sociocultural dos alunos.

Esses resultados também mostram que uma contribuição importante do Programa Etnomatemática para o desenvolvimento da Educação Financeira dos alunos Surdos foi evidenciar o respeito e a atenção à sua cultura e, também, de suas vivências cotidianas, pois foram relevantes para a promoção de uma relação significativa entre o conhecimento matemático adquirido no dia a dia com aquele sistematizado pela escola.

Além disso, pode-se inferir que as estratégias utilizadas em sala de aula, como, por exemplo, a utilização da Libras por meio de sua tecnoracia, o auxílio dos próprios participantes para explicar os conteúdos e as atividades, os problemas contextualizados, as dinâmicas propostas, as atividades lúdicas e as simulações de situações-problema cotidianas, contribuíram para o entendimento de conteúdos relacionados com a Educação Financeira.

Assim, a Etnomatemática possibilitou a promoção da reflexão sobre o processo de ensino e aprendizagem em matemática com relação aos conteúdos relacionados com a Educação Financeira, bem como sobre o papel dessa área de conhecimento na construção da cidadania. Nesse direcionamento, o propósito da Etnomatemática para esse estudo foi evidenciar e anali- 
sar uma proposta pedagógica contextualizadora da Cultura Surda e do meio social dos alunos Surdos.

Por conseguinte, Rosa (2010) argumenta que a Etnomatemática relaciona a matemática escolar com o cotidiano, pois, para que os alunos possam aprender conteúdos matemáticos, existe a necessidade de que analisem os fenômenos que ocorrem em suas próprias comunidades. Assim, o Programa Etnomatemática possibilitou a superação das barreiras da comunicação, propiciando oportunidades para os alunos Surdos transcenderem e desenvolverem as suas potencialidades matemáticas para o pleno exercício da cidadania.

\section{CONSIDERAÇÕES FINAIS}

É importante ressaltar que, de acordo com D’ Ambrosio (1998), um conhecimento prático que pode favorecer o desenvolvimento dos alunos nas escolas está relacionado com a utilização de recursos tecnológicos, como, por exemplo, os computadores e as calculadoras em sala de aula. Desse modo, ressalta-se que se uma:

(...) criança de classe pobre não vê na escola um computador, como jamais terá oportunidade de manejá-lo em sua casa, estará condenada a aceitar os piores empregos que se lhe ofereçam. Nem mesmo estará capacitada para trabalhar como caixa num grande magazine ou num banco. É inacreditável que a educação matemática ignore isso. Ignorar a presença de computadores e calculadoras na educação matemática é condenar os estudantes a uma subordinação total a subempregos (D’AMBROSIO, 1998, p .17).

Nesse direcionamento, Alves (2014) argumenta que é importante a proposição de discussões sobre a importância dos recursos tecnológicos para o desenvolvimento dos alunos nas salas de aula, pois é "inadmissível pensar hoje em aritmética e álgebra, que privilegiam o raciocínio quantitativo, sem a plena utilização de calculadoras" (D’AMBROSIO, 2009, p .43).

Assim, D’Ambrosio (2008) afirma que a "educação resulta da dinâmica do encontro cultural de gerações, o encontro do 'velho', o professor, e do 'novo', o aluno" (p. 12). Por conseguinte, para Alves (2014), nesse "dinamismo cultural, também existe a necessidade de haver o encontro das velhas tecnologias, como lápis e papel, com novas tecnologias, como calculadoras e computadores" (p. 46). Esse encontro possui relações diretas com a tecnoracia, que é proposta por D’Ambrosio (1999) para o Currículo Trivium para a Matemática.

Nesse estudo, o Programa Etnomatemática possibilitou a utilização de instrumentos materiais e tecnológicos próprios da cultura Surda para que os seus membros pudessem manifestar as diversas habilidades para lidar com o contexto sociocultural em que estão inseridos, por meio do desenvolvimento das próprias técnicas e procedimentos para explicar, entender e compreender os saberes e fazeres difundidos e compartilhados de geração em geração (D’AMBROSIO, 1990). 
Desse modo, o principal objetivo do processo de ensino e aprendizagem em Matemática, para a Educação Financeira, deve ser o desenvolvimento de uma "educação [que] possibilite, ao educando, a aquisição e utilização dos instrumentos comunicativos, analíticos e materiais que serão essenciais para seu exercício de todos os direitos e deveres intrínsecos à cidadania" (D'AMBROSIO, 2009, p .66).

De acordo com Alves (2014), a utilização de metodologias convencionais aliadas a novos métodos de trabalho pedagógico pode auxiliar os alunos no desempenho matemático, bem como na realização das tarefas curriculares relacionadas com a resolução de problemas enfrentados no cotidiano. Portanto, concordamos que existe a necessidade da utilização dos recursos, das tecnologias e do conhecimento dos conteúdos da Educação Financeira no processo de tomada de decisões. Contudo, apesar dos conhecimentos tecnológicos disponíveis na atualidade, ainda se convive com muitas tomadas de decisão financeira realizadas sem que os custos e benefícios sejam analisados (ALVES, 2014).

Para D'Ambrosio (2009), citado em Alves (2014), educar financeiramente é uma ação ampla, que inclui o processo de ensino e aprendizagem em Matemática para que os alunos possam compreender as situações comerciais e financeiras, entender o comportamento do dinheiro no tempo, organizar conscientemente as suas finanças pessoais, discutir matematicamente a utilização consciente do crédito, entender temas de economia relacionados com a inflação por meio da utilização de instrumentos materiais e tecnológicos para auxiliá-los na resolução de situações-problema presentes no cotidiano podendo refletir e analisar crítica e matematicamente esses fenômenos.

No processo desenvolvido nesta pesquisa, os alunos Surdos, membros da Cultura Surda, acrescentaram à sua realidade os artefatos, que são as suas representações da realidade, bem como as tecnologias e as expressões materiais que estão relacionadas com a sua experiência material, por meio da utilização da Libras e das suas próprias tecnoracias através da comunicação gesto-visual.

Por exemplo, é necessário que as atividades matemáticas explorem o aspecto visual dos conteúdos, sendo importante que as intervenções pedagógicas sejam planejadas para atender as especificidades dos alunos Surdos (NUNES et al., 2013). Uma maneira de aumentar o acesso dos alunos Surdos aos conceitos e conteúdos matemáticos é por meio da exploração da utilização de representações visuais e espaciais (BULL, 2008). Então, é importante que esses alunos tenham oportunidades para utilizarem as suas habilidades visuais e espaciais para poder representar e manipular as informações presentes nos problemas matemáticos (NUNES, 2004), e desenvolver, assim, a sua tecnoracia por meio da utilização da Libras.

Dessa maneira, a utilização dos recursos materiais e tecnológicos contribuiu para a formação de indivíduos aptos a intervir em uma sociedade na qual a tecnologia ocupa um espaço cada vez mais importante (D’AMBROSIO, 2009), para que se possa educar financeiramente os alunos. Para transformá-los em cidadãos ativos na sociedade, existe a necessidade de fornecerlhes informações tecnológicas que os auxiliem no entendimento e na compreensão dos conteúdos da Educação Financeira. 


\section{REFERÊNCIAS}

ALVES, Gelindo Martineli. As contribuições da etnomatemática e da perspectiva sociocultural da história da matemática para a formação da cidadania dos alunos de uma turma do 8. ${ }^{\circ}$ ano do ensino fundamental por meio do ensino e aprendizagem de conteúdos da educação financeira. 2014. Dissertação (Mestrado Profissional em Educação Matemática) Universidade Federal de Ouro Preto, Ouro Preto.

BRASIL. Parâmetros curriculares nacionais: matemática. Secretaria de Educação Fundamental, Brasília: MEC/SEF, 1998.

BULL, Rebecca. Deafness, numerical cognition, and mathematics. Deaf cognition: Foundations and outcomes, Oxford University Press, New York, NY, p. 170-200, 2008.

D'AMBROSIO, Ubiratan. Etnomatemática: arte ou técnica de explicar e conhecer. [S.l.]: Editoria Ática, 1998.

D'AMBROSIO, Ubiratan. Literacy, matheracy, and technocracy: A trivium for today. Mathematical Thinking and Learning, Routledge, v. 1, n. 2, p. 131-153, 1999.

D’AMBROSIO, Ubiratan. Etnomatemática-elo entre as tradições e a modernidade. Belo Horizonte: Autêntica, 2009.

D’AMBROSIO, Ubiratan. Etnomatemática. Editora Ática, São Paulo, SP, Brasil, 1990.

D’AMBROSIO, Ubiratan. Educação numa era de transição. Revista Matemática \& Ciência, v. 1, n. 1, p. $8-18,2008$.

GIL, Rita Sidmar Alencar. Educação Matemática dos Surdos: um estudo das necessidades formativas dos professores que ensinam conceitos matemáticos no contexto de educação de deficientes auditivos em Belém do Pará. 2008. Dissertação (Mestrado em Educação) Universidade Federal do Pará, Belém, PA.

NUNES, Terezinha. Teaching mathematics to deaf children. London, UK: Whurr Publishers, 2004.

NUNES, Terezinha et al. Promovendo o sucesso das crianças surdas em matemática: uma intervenção precoce. Cuadernos de Investigación y Formación en Educación Matemática, v. 8, n. 11, p. 263-275, 2013.

PINHEIRO, Rodrigo Carlos. Contribuições do programa etnomatemática para o desenvolvimento da educação financeira de alunos Surdos que se comunicam em Libras. 2017. Dissertação (Mestrado) — Departamento de Educação Matemática. MG: Universidade Federal de Ouro Preto, Ouro Preto.

ROSA, Milton. A mixed-methods study to understand the perceptions of high school leaders about english language learners (ELLs): The case of mathematics. 2010. Tese (Doutorado) - CA: California State University.

ROSA, Milton; OREY, Daniel Clark. Abordagens atuais do programa etnomatemática: delineando um caminho para a ação pedagógica. Bolema, Rio Claro, v. 19, n. 26, p. 19-48, 2006.

ROSA, Milton; OREY, Daniel Clark. A trivium curriculum for mathematics based on literacy, matheracy, and technoracy: an ethnomathematics perspective. ZDM, v. 47, n. 4, p. 587-598, Jul 2015. ISSN 1863-9704. Disponível em: <https://doi.org/10.1007/s11858-015-0688-1>. 
SANTOS, Monica Bertoni dos. Saberes de uma prática inovadora: investigação com egressos de um curso de licenciatura plena em matemática. 2005. Dissertação (Mestrado em Ciências e Matemática) - Pontifícia Universidade Católica do Rio Grande do Sul, Porto Alegre.

STROBEL, Karin. As imagens do outro sobre a cultura surda. [S.1.]: Editora da UFSC Florianópolis, 2008. 